\title{
Case Report \\ Management of glaucoma in a case of familial aniridia by trabeculectomy
}

\author{
Barthakur R ${ }^{1}$, Shrestha $\mathrm{S} \mathrm{P}{ }^{1}$, K Bhat $\mathrm{S}^{2}$, Natarajan $\mathrm{M}^{1}$ \\ ${ }^{1}$ Department of Ophthalmology, Manipal Teaching Hospital, \\ Manipal College of Medical Sciences, Pokhara, Nepal \\ ${ }^{2}$ Department of Ophthalmology, K S Hegde Medical Academy, Mangalore, India
}

\begin{abstract}
Aniridia is a rare developmental disorder. Glaucoma and complications associated with glaucoma surgery are a major cause of blindness in patients with aniridia. We describe here a case of a nine year old boy who presented with familial aniridia of both eyes along with glaucoma. He was treated by trabeculectomy of both eyes, which was successful in controlling the glaucoma.
\end{abstract}

Key words: Aniridia, glaucoma, trabeculectomy

\section{Introduction}

Aniridia is a rare developmental disorder occurring once in 100,000 births (Shaw et al 1960). This disorder also affects the cornea, anterior chamber angle, lens, retina and optic nerve (Hittner, 1989 and Nelson et al 1984). Other ocular manifestations include macular and optic nerve hypoplasia, glaucoma, strabismus, lens abnormalities like cataract and subluxation, corneal changes and pendular nystagmus. Aniridia may be familial or sporadic and is categorized into Type $1[85 \%$, familial], Type 2 [13\%, Miller's syndrome, may be associated with Wilms' tumour], and Type 3 [2\%, Gillespie's syndrome, not associated with Wilms' tumour]. Glaucoma and complications associated with glaucoma surgery are a major cause of blindness in patients with aniridia (Nelson et al 1984). We report here a case of familial aniridia with glaucoma who was treated successfully by trabeculectomy in both eyes.

\section{Case report}

A nine year old male presented with a history of a whitish reflex in the centre of the eyes since 3-4 months of age, progressively poor vision since early childhood, excessive blinking and aversion to light. The patient

Received: 26.08.2008. Accepted: 04.10.2008

Correspondence and reprint requests to: Dr Rimli Barthakur, MS

Department of Ophthalmology, Manipal Teaching Hospital, Manipal

College of Medical Sciences, Phulbari, Pokhara, Nepal.

email: rimli.barthakur@gmail.com

Tel : 00977-61-526416, Ext : 146 had been delivered at term normally and all developmental milestones had been reached on time. There was a significant family history of the mother having a similar disorder. The patient's father and two siblings did not have any eye problems.

The general and systemic examinations of the patient were normal and he was of normal intelligence.

Visual acuity was finger counting $[\mathrm{FC}]$ close to face in the right eye $[\mathrm{R} / \mathrm{E}]$ and $\mathrm{FC}$ at 0.5 metres in the left eye $[\mathrm{L} / \mathrm{E}]$. Both eyes showed pendular nystagmus. Lids and conjunctivae were normal bilaterally. The cornea was hazy in both eyes with some scattered opacities (Fig.1). Clinically, there was bilateral aniridia. The lens showed immature cataract and was subluxated superiorly in both eyes (Fig. 2). The intraocular pressure [IOP] as measured by Schiotz tonometry was $41 \mathrm{mmHg}$ in $\mathrm{R} / \mathrm{E}$ and $29 \mathrm{mmHg}$ in $\mathrm{L} / \mathrm{E}$. Dilated fundoscopy revealed glaucomatous cupping of $0.5-0.6$ in $\mathrm{R} / \mathrm{E}$ and $0.4-0.5$ in L/E.

Routine blood and urine examination, abdominal ultrasound and chest $\mathrm{x}$-ray were normal.

The mother was found to have aniridia and ptosis in both eyes, but no glaucoma.

A diagnosis of familial aniridia with glaucoma was made. The patient was admitted, put on timolol maleate [0.5\%] eye drops and posted for examination under anaesthesia (EUA) and trabeculectomy of the right eye. 
On EUA, the corneal diameters in both eyes were within normal limits. The IOP in both eyes were $51 \mathrm{mmHg}$. Trabeculectomy was done in the right eye. No adjunctive antimetabolite was used.

The post-operative period was uneventful and the patient was discharged on the $6^{\text {th }}$ post-operative day on timolol maleate $[0.5 \%]$ eye drops in both eyes and prednisolone acetate eye drops in the R/E. IOP was 29 $\mathrm{mm} / \mathrm{Hg}$ in $\mathrm{R} / \mathrm{E}$ and $12.2 \mathrm{mmHg}$ in $\mathrm{L} / \mathrm{E}$. Visual acuity was light perception in $\mathrm{R} / \mathrm{E}$ and $\mathrm{FC}$ at 0.5 metres in $\mathrm{L} / \mathrm{E}$.

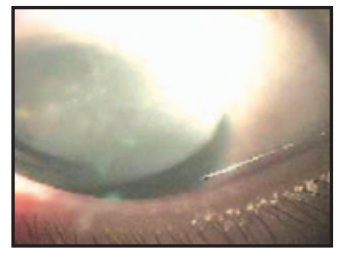

Figure 1: Hazy cornea with some scattered opacities

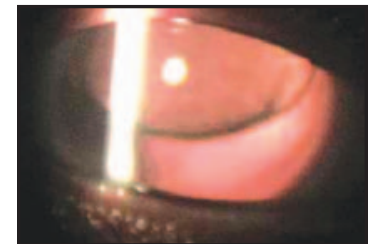

Figure 2: Lens showing immature cataract and subluxation superiorly
Post-operative follow-up, weekly for two weeks and monthly thereafter, showed a steady fall in IOP in R/E to $18.9 \mathrm{mmHg}$, decrease in corneal haziness and improvement in visual acuity to FC at 1.5 metres, and timolol maleate eye drops was stopped. In the L/E, IOP, however, increased gradually to $50 \mathrm{mmHg}$, but visual acuity was maintained at $\mathrm{FC}$ at 0.5 metres. $2 \%$ pilocarpine eye drops was added in the left eye, but IOP did not decrease. Trabeculectomy was done in the left eye, three months after the surgery in the right eye. No adjunctive antimetabolite was used.

The patient was discharged after one week with an IOP of $29 \mathrm{mmHg}$ in $\mathrm{L} / \mathrm{E}$ and $18.8 \mathrm{mmHg}$ in R/E.

On monthly follow-up, the IOP further decreased to $18.9 \mathrm{mmHg}$ in $\mathrm{L} / \mathrm{E}$ and was maintained at $20 \mathrm{mmHg}$ in $\mathrm{R} / \mathrm{E}$. The corneal haziness had also decreased significantly. Refraction was done through the aphakic part of the subluxated lens in both eyes and vision improved to $5 / 60$ in both eyes with $+11 \mathrm{D}$ lens. The patient has been on follow-up at four monthly intervals for the last four years and the IOP has been maintained at a normal level with a corrected visual acuity of 5/60 in both eyes. The glaucomatous disc cupping has not increased. The child can manage all his daily activities and is in a school for the visually handicapped.

\section{Discussion}

The incidence of glaucoma reported in aniridia is markedly variable depending on the series and occurs mainly due to two mechanisms (Nelson et al 1984). In the familial form, angle closure glaucoma mainly occurs due to progressive apposition of the rudimentary iris to the trabecular meshwork. Severe developmental angle abnormalities lead to glaucoma in Type 2 aniridia. Glaucoma may be controlled initially by medical therapy, but surgery is eventually required in most cases. Filtration procedures bear a high risk of vitreous haemorrhage and cataract formation or progression (Nelson et al 1984). Goniotomy may be effective in preventing aniridic glaucoma (Chen and Walton, 1999); however, treatment of established glaucoma is disappointing. Trabeculotomy has been suggested as the preferred initial operation by some (Adachi et al 1997), but it also has risks and repeat surgery may be necessary. Most authorities have recommended trabeculectomy for control of aniridic glaucoma. This procedure has been shown to be effective in controlling IOP in young patients (Okada et al 2000). Failure and need for re-operation have also been reported (Nelson et al 1984). Cyclocryotherapy may be necessary in some cases, though it may lead to complications (Hittner, 1989).

In our patient, due to the presence of significant glaucomatous damage and high IOP, the decision was taken for trabeculectomy on the right eye without delay. The IOP of the L/E was controlled initially by medications, but later trabeculectomy had to be performed. Good control of IOP has been achieved in both eyes following surgery.

\section{References}

Adachi M, Dickens CJ, Hetherington J Jr, Hoskins HD, Iwach AG, Wong PC et al (1997).

Clinical experience of trabeculotomy for the surgical treatment of aniridic glaucoma. Ophthalmology 104(12): 2121-5.

Chen TC, Walton DS (1999). Goniosurgery for prevention of aniridic glaucoma. Arch Ophthalmol 117(9): 1144-8.

Hittner H (1989). Aniridia. In Ritch R, Shields M, Krupin T (eds): The Glaucomas. St. Louis CV Mosby.

Nelson LB, Spaeth GL, Nowinski T et al (1984). Aniridia: A review. Surv Ophthalmol. 28:621.

Okada K, Mishima HK, Masumoto M, Tsumamoto Y, Tsukamot H, Takamatsu M (2000). Results of filtering surgery in young patients with aniridia. Hiroshima J Med Sci. 49(3): 135-8

Shaw M, Falls H, Neel J (1960). Congenital aniridia. Am J Hum Genet. 12:389. 